\title{
Dysgraphia in Relation to Cognitive Performance in Patients with Alzheimer's Disease
}

\author{
Emanuela Onofri ${ }^{1}$, Marco Mercuri ${ }^{1}$, MariaLucia Salesi ${ }^{1}$, Salvatore Ferrara ${ }^{1}$, \\ Giulia Maria Troili ${ }^{1}$, Francesco Massoni ${ }^{1}$, Claudio Simeone ${ }^{1}$, Max Rapp Ricciardi ${ }^{2}$, \\ Serafino Ricci ${ }^{1}$ and Trevor Archer ${ }^{2, *}$ \\ ${ }^{1}$ Department of Anatomy, Histology, Legal Medicine and Orthopedics, Sapienza University of Rome, Italy \\ ${ }^{2}$ Department of Psychology, University of Gothenburg, Gothenburg, Sweden
}

\begin{abstract}
Dysgraphia has been observed in patients presenting mild to moderate levels of Alzheimer's disease (AD) in several studies. In the present study, $30 \mathrm{AD}$ patients and 30 matched healthy controls, originating from the Lazio region, Rome, Italy, were examined on tests of letter-writing ability and cognitive performance over a series of 10 test days that extended over 19 days (Test days: 1, 3, 5, 7, $911,13,15,17$, and 19). Consistent deficits by the AD patients over the initial cognition test (PQ1), $2^{\text {nd }}$ cognition test (PQ2) and the difference between them (D $\Delta$ ), expressing deterioration, and writing-time compared the group of healthy control subjects were obtained. Furthermore, the performances of the $A D$ patients on the PQ1, D $\Delta$ and writing-time, but not the PQ2, tests deteriorated from the $1^{\text {st }}$ five days of testing (Days 1-9) to the $2^{\text {nd }}$ five days (11-19). Both AD patients' and healthy controls' MMSE scores were markedly and significantly correlated with performance of PQ1, writing-time and PQ2. The extent of dysgraphia and progressive deficits in the AD patients implicate multiple brain regions in the loss of functional integrity.
\end{abstract}

Keywords: Dysgraphia, cognition, deficit, patients, healthy controls, PQ1, writing-time, PQ2, MMSE, deterioration, Alzheimer's disease.

\section{INTRODUCTION}

Writing skill may represent procedural/implicit memory, and dysgraphia errors indicating alterations in long-term memory in dementia of the Alzheimer type (Alzheimer's disease, AD, [1]. Under clinical conditions, dysgraphia presents a deficiency in the ability to write, primarily in terms of handwriting but also in terms of coherence is a transcription disability, implying that it is a writing disorder associated with impaired handwriting [2], In 1907, Alzheimer [3] had observed in these patients abnormal graphic gestures which indicated that hand writing is not constituted by a unitary process, but requires a coordination of the linguistic, visual-spatial and motor domains of the individual [4, 5]. The disruption of these functions reflects brain damage in different associative areas, such as parietal, temporal, occipital and frontal regions and covering different domains, e.g. cognition, language and motor, [6], and subsequently was diagnosed in AD patients [7]. Lambert et al. [8] have demonstrated a wide variety of agraphia syndromes, including a far from negligible number of patients with selective damage to one of the central or peripheral components, as well as patients with multiple writing impairments with positive correlation was observed between the severity of the dementia and spelling/writing measures (lexical and

*Address correspondence to this author at the Department of Psychology, University of Gothenburg, Gothenburg, Sweden; Tel: +46317864694; Fax: +46317864628; E-mail: trevor.archer@psy.gu.se allographic). Agraphia or dysgraphia, observed in early $A D$ [9], encompasses a progressive disorganization and degeneration of the various components of handwriting [10]. In the language domain, these disturbances are captured in several ways of expressing speech and writing, such as the complexity of the structure of sentences [11], the diversity, organization and the accuracy of words used and several aspects of language application [1, 5, 12-15]. Fukui and Lee [16] examined the possibility that agraphia/dysgraphia may be an early sign of degenerative dementia, reporting the concurrent or subsequent emergence of non-fluent aphasia, ideomotor apraxia, executive dysfunction and asymmetric akinetic-rigid syndrome that implicated degenerative processes involving the parietal-occipitaltemporal regions, basal ganglia and striato-frontal projections. It has been observed that that writing impairment is heterogeneous within the AD population, but nevertheless, there are certain aspects of the writing process that are more vulnerable than others and may present diagnostic signs [17]. Neuro-imaging with MRI, for example, has indicated marked structural defects in patients: Atrophy in the left hemisphere supramarginal gyrus and inferior frontal gyrus (IFG) pars orbitalis correlated with errors in non-word spelling, while thinning in the left temporal pole and fusiform gyrus correlated with errors in exception word spelling [18]. Additionally, in the language domain there is much support for the notion of semantic agraphia in AD [19]. 
There is a consensus that dysgraphia arises invariably during the clinical course of dementia [20]. It may be termed "central" if generated at a level that affects spelling or "peripheral" if spelling is correctly generated but the peripheral procedures are not activated properly. The progression of dysgraphia in AD patients seems proportional to the extent of central (linguistic system) and peripheral (allographic or grapho-motor system) as an expression of the disorder staging [21, 22] that increases the dysfunction disproportionately [23, 24]. The syndrome may appear relatively early in the onset of $A D[25,26]$, as a more sensitive indicator of language deficits than anomia, deficits in the naming of persons/objects [27, 28]. The specific patterns of dysgraphia include lexical or surface dysgraphia [29], phonological dysgraphia [30] and peripheral dysgraphia [31, 32]. AD is associated with visuospatial and language dysfunctions in the disorder pathophysiology with bilateral involvement of the temporoparietal-frontal lobes [33]. In a study of dysgraphia in early-onset $A D$, linguistic and visuospatial writing errors were observed with severity of dementia and multiple cognitive domains, including language, attention, immediate memory and frontal executive functions correlated markedly with Hangul writing performance [34]. It would appear that the writing disturbances expressed in $A D$ patients are heterogenous encompassing phonological dysgraphia, lexical dysgraphia and mixed dysgraphia [35]. Several brain regions have been linked to dysgraphia, e.g. the left inferior parietal lobule [36], the left posterior temporal area [37] and the left posterior middle frontal gyrus [38].

The purpose of the present study was to examine the extent of dysgraphia and cognitive performance on a specially-adapted test of cognition in a group of 30 $A D$ patients presenting a moderate level stage of the disorder according to MMSE estimations (see below), and in a matched group of 30 healthy controls, and the relationship between dysgraphia, functional assessment (MMSE) and performance (PQ1 and PQ2).

\section{METHODS AND MATERIALS}

\section{Participants}

There were 30 patients who were selected to participate in the study, 12 male and 18 female $A D$ patients, who met both the inclusion criteria (see Table 1, below) and the exclusion criteria, i.e. absence of other neuropsychiatric disorders. The age was between 73 to 94 years of age (mean age: 83.06, SD: 6.15). All of the patients were presenting symptoms that indicated a diagnosis of $A D$ from moderate level to relatively severe (see Table $\mathbf{1}$ ). All of these diagnoses were confirmed and verified by resident neurologists at the Department of Neurology at the hospital (Gemelli University Polyclinicl-service neuro psychology, Roma and UVA (Alzheimer Evaluation Unit) ASLRMF and UVA (Alzheimer Evaluation Unit) ASLRMD, 26 patients and 4 patients from the Department of Neurology and Psychiatry, Sapienza Hospital, Rome) in the Lazio (Rome, Italy) region. The diagnosis was based on normal or nonspecific EEG and lateral, occipital brain atrophy on CT brain with documented progression after serial observations, on cognitive test and routine blood tests that aimed at excluding the presence of other medical conditions that can justify dementia. Patients were excluded if they had a history of known or suspected cerebrovascular disease, focal neurological signs or on brain imaging, alcohol misuse, head trauma, significant psychiatric history preceding the current diagnosis or other major physical illness. The clinical characteristics of the participants in the study are presented in Table 1. They were diagnosed according to the NINCDS-ADRDA criteria [39], and to the DSM-IV diagnostic reference. The mean length of time spent upon education by the 30 patients was 11.06 years $(S D \pm 3.6$ years). A considerable amount of time (regular meetings during 3 months) was invested in each of the patients in order to promote a relationship of trust and understanding, as well as to reduce stress factors [5] that may affect patients' mood and attentiveness, or, more seriously, induce behaviors that suggest hallucinations or auditory illusions, paranoid delirium, difficulty to recognize persons, or loss of cognition of time and places. All the procedures that were adopted according to discussions and meetings with nearest relatives in order to obtain the consent of the patients as well as those relatives (in those cases were the latter were their caregivers/legal representatives) according to the legal practices. The control group of age- and education-matched healthy senior citizens was chosen as individuals that were not in any way influenced by $A D$ and whom presented the following characteristics: mean age 82.73 years (SD \pm 5.7 years). The mean amount of time spent upon education by the healthy controls was 12.8 years (SD \pm 4.04 years).

AD diagnosis: All the patients evidenced lower performance in the standard tests of neuropsychological assessment that were administered. The cognitive profiles presented by these patients expressed 
Table 1: Clinical Characteristics and Neurological Data of each of the AD Patients in the Present Study

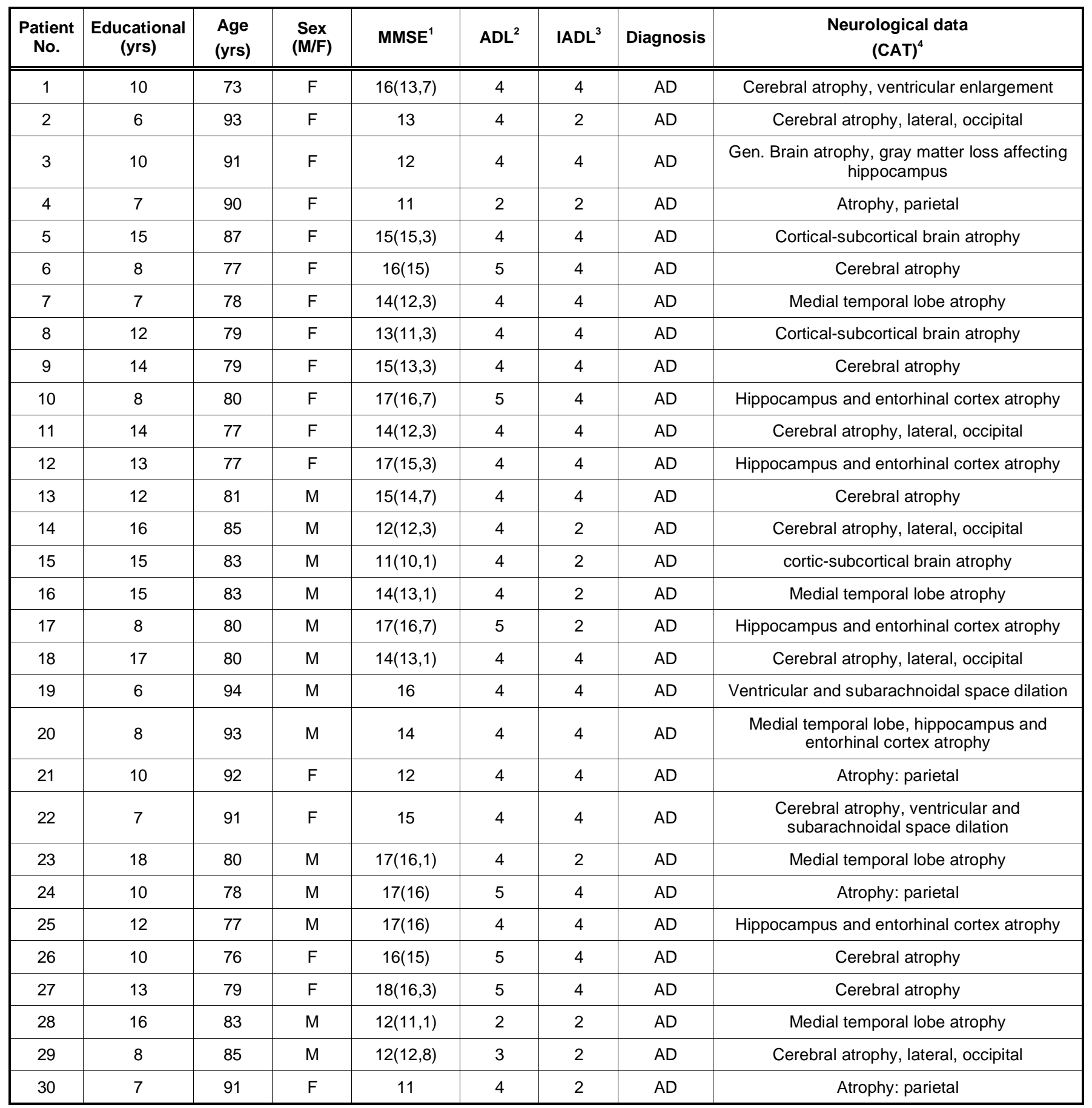

${ }^{1} \mathrm{MMSE}=$ mini-mental state examination [41] [normal level score $=30$ points], modified by age and education (numbers in brackets); ${ }^{2} \mathrm{ADLs}=\mathrm{Activities}$ of $\mathrm{Daily}$ living [42] [normal level=6/6 for both males and females]; ${ }^{3} \mathrm{IADLs}=$ Instrumental activities of daily living [43] [normal level=8/8 for both males and females]; $A D=A \mid z h e i m e r ' s$ disease; ${ }^{4}$ Computerized axial tomography. Gen. = generalized.

cognitive impairments that were widespread and related to a severe dementia syndrome of a progressive nature that was linked to a degenerative dementia of the Alzheimer type. On the basis of the neuropsychological tests and clinical observations this group of patients was classified at the moderate to relatively severe stage of $A D$ [40].
Mini-mental State Examination (MMSE) presents a brief 30-point questionnaire test to screen for cognitive impairment and dementia [41]. It estimates the severity of disorder and follows the course of cognitive changes in an individual over time, thereby allowing effective monitoring of an individual's response to treatment. Table 1 presents the individual 
scores of each of the patients. It will be noted that these scores range from 11 to 18 which implies that the patients express a moderate level of $A D$ disorder. Healthy control individuals scored at 30 points.

Activities of Daily Living (ADLs) offers an instrument that measures everyday behaviors necessary for normal functioning on a daily basis [42]. Under normal conditions, individuals must invest a certain amount of time taking care of their personal care and hygiene in order to promote their own health and to a sufficiency of independent initiative and capability.

Instrumental Activities of Daily Living (IADLs) offers an instrument that measures those behaviors that are linked to an independent lifestyle. The instrument has been found to be useful for evaluations of individuals presenting early-stage (or moderate stage) disorders: it has been found applicable for ascertaining both disorder extent and determination of individual capacity for self-care and management [43].

Neurological data for structural neuro-imaging analysis was obtained from computerized axial tomography (CAT) whereas magnetic resonance imaging (MRI) data were not available.

\section{Writing (Graphia) Test and Memory Tests}

Each patient was provided with a writing-pad for writing texts or drawing figures, preferably the "vergatina" type (flimsy type, typing paper or tissue type or absorbent) in order to avoid false interpretations of the writings to analyze. A ballpoint pen was used throughout. The patients were invited to sit comfortably at a writing desk. The memory test material consisted of the presentations of a 14-item questionnaire involving questions regarding semantic knowledge as well as spatial and temporal orientation that were modifications of questions that were derived partially from the MMSE and then modified. The questionnaires were handled easily and could be presented to patients by different medical practitioners. Points were assigned on the basis of the complexity of each of the questions.

The total sum from each test session was represented by $P Q$ : the initial session result designated $P Q 1$ and the test session following the letter-writing, graphia, test was designated PQ2. Following the PQ1 memory test, each patient was presented a writing-pad and asked to write a letter to a close relative. On consecutive days of testing patients were invited to write to either the same relative or another one. Using a chronometer to establish length of writing-time ( $\mathrm{min}$.), the letter-writing task was interrupted when it seemed that the text produced by the patient was substantially (pathologically) confused (both with regard to spatial disorientation as well as for a sudden lack of readability, disjointedness and incompleteness in meaning). After this, the number of minutes (min) that had been reached for each single patient was registered. The whole procedure involving the letterwriting graphia task was interrupted after 20 minutes. Directly after the letter-writing, the list of 14 questions presented in PQ1 was presented again in a repeated procedure that was designated $P Q 2$. The difference between these two measures (PQ1-PQ2) was designated $\mathrm{D} \Delta$. These procedures for testing: 14-item test - graphia test - 14-item test were presented in an identical manner every second over 10 days (Days 1 , $3,5,7,9,11,13,15,17$, and 19) at the same hour-ofday on test days in order to hold constant testing procedures over daily curriculum and any clinical interventions that the patients may be subject to.

\section{Statistical Analysis}

The results consisting of PQ1 and PQ2 scores, min spent writing and $\mathrm{D} \Delta$ (see above) was calculated as means and standard deviations of the AD patient group and the healthy control group over consecutive days of testing. Pearson's correlation coefficient was used to assess the relationship between writing-time and PQ1 and writing-time over both patients and matched healthy controls for each of the test days. Student's ttests were used to test for pairwise differences for each of the parameters. Pearson's correlation coefficient was used to assess the relationship between MMSE scores and PQ1, writing-time and PQ2.

\section{RESULTS}

\section{Correlational Analyses: Writing-Time and PQ1}

Significant and linear correlations were obtained between length of writing-time by patients and their performance on PQ1, the initial test of cognition, on every single day of testing, from Test day 1 to Test day 19 , indicating that the extent of dysgraphia, expressed here as an inadequacy to write letters to a close relative, was functionally related to poor performance during PQ1. The one exception to this pattern was Test day 13 wherein a somewhat better cognitive performance (PQ1) was associated with a slightly higher extent of dysgraphia. Figure 1 presents the 

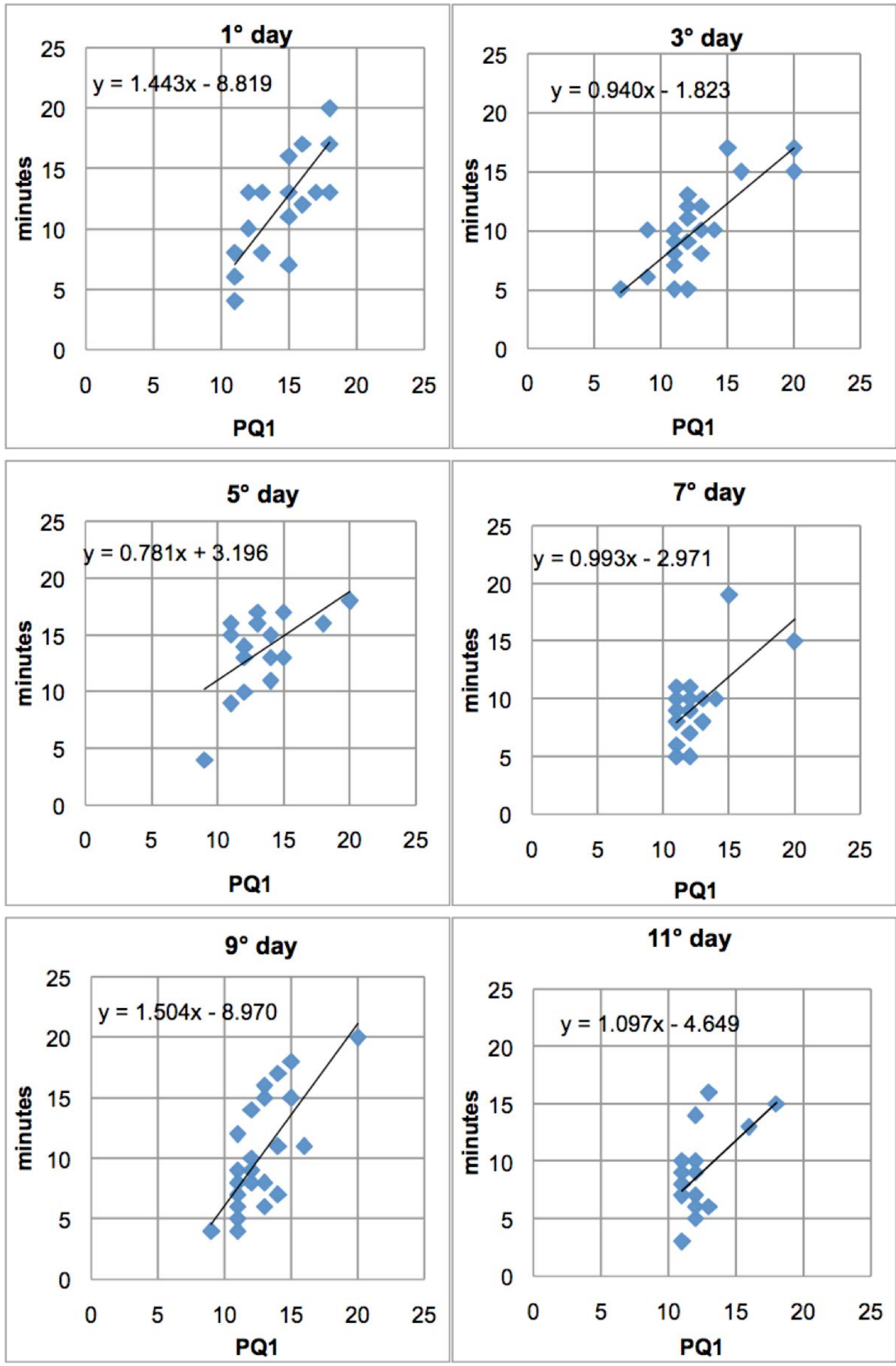
(Figure 1). Continued.
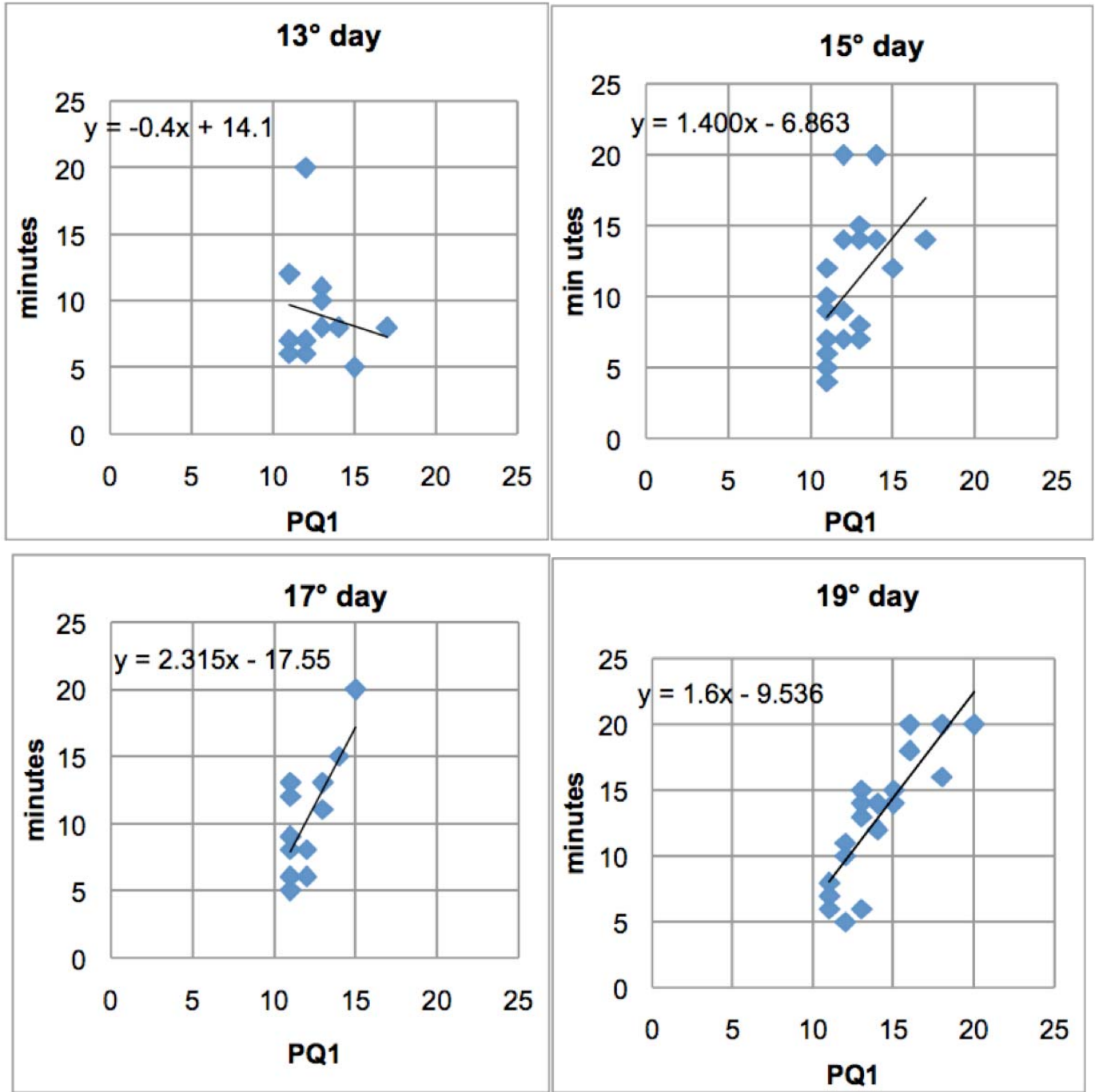

Figure 1: Correlational analysis (Pearson product moment) between PQ1 and writing-time (min) by AD patients from Test day 1 to Test day 19 (10 days of testing). The correlation coefficients were: Day $1: 0.802^{\star}$; Day $30.785^{*}$; Day $50.603^{\circ}$; Day $70.644^{\circ}$;

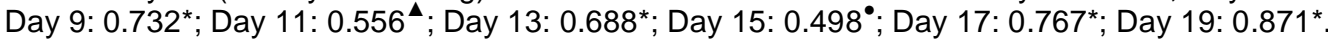

${ }^{*} p<0,0001 .{ }^{\circ} p<0.005 ;{ }^{\wedge} p<0.002 ;{ }^{\circ} p<0.001$, Pearson Product moment correlations.

Pearson Product moment correlations and slopes on each of the 10 test days for the AD patients.

The correlational analysis of the matched healthy controls differed markedly from that of the AD patients in that only those of Test Days 15, 17 and 19 achieved significance but only a few individuals performed letterwriting and the cognitive test at a level just below maximum scoring. Indeed, maximal performance on both letter-writing and PQ1 defined the output of the healthy controls. The correlations (below) indicate these differences clearly. Figure 2 presents the Pearson Product moment correlations and slopes on each of the 10 test days for the healthy controls.

The performance of the $A D$ patients over all the tests applied, PQ1, PQ2, D 4 , which expresses the deterioration from PQ1 to PQ2, and letter-writing, was significantly impaired compared with the healthy control group (See Tables 2 and 3). It was observed also that for PQ1, D $\Delta$ and writing-time, that performance deteriorated from Test Days 1-9 to 11-19, but improved slightly for PQ2. Table 2 presents the performance of $A D$ patients on the tests of cognition, PQ1 and PQ2, the difference between these tests, $\mathrm{D} \Delta$, and in the writing test.

The performance of the healthy control remained relatively constant over the testing parameters, PQ1, $P Q 2$, $D \Delta$, which expresses the deterioration from $P Q 1$ to $P Q 2$, and letter-writing, and the 10 days of testing. Nevertheless, it was observed that for both PQ1 and PQ2 their performance was slightly, significantly worse from Test days 1-9 to 11-19. Table 3 presents the 

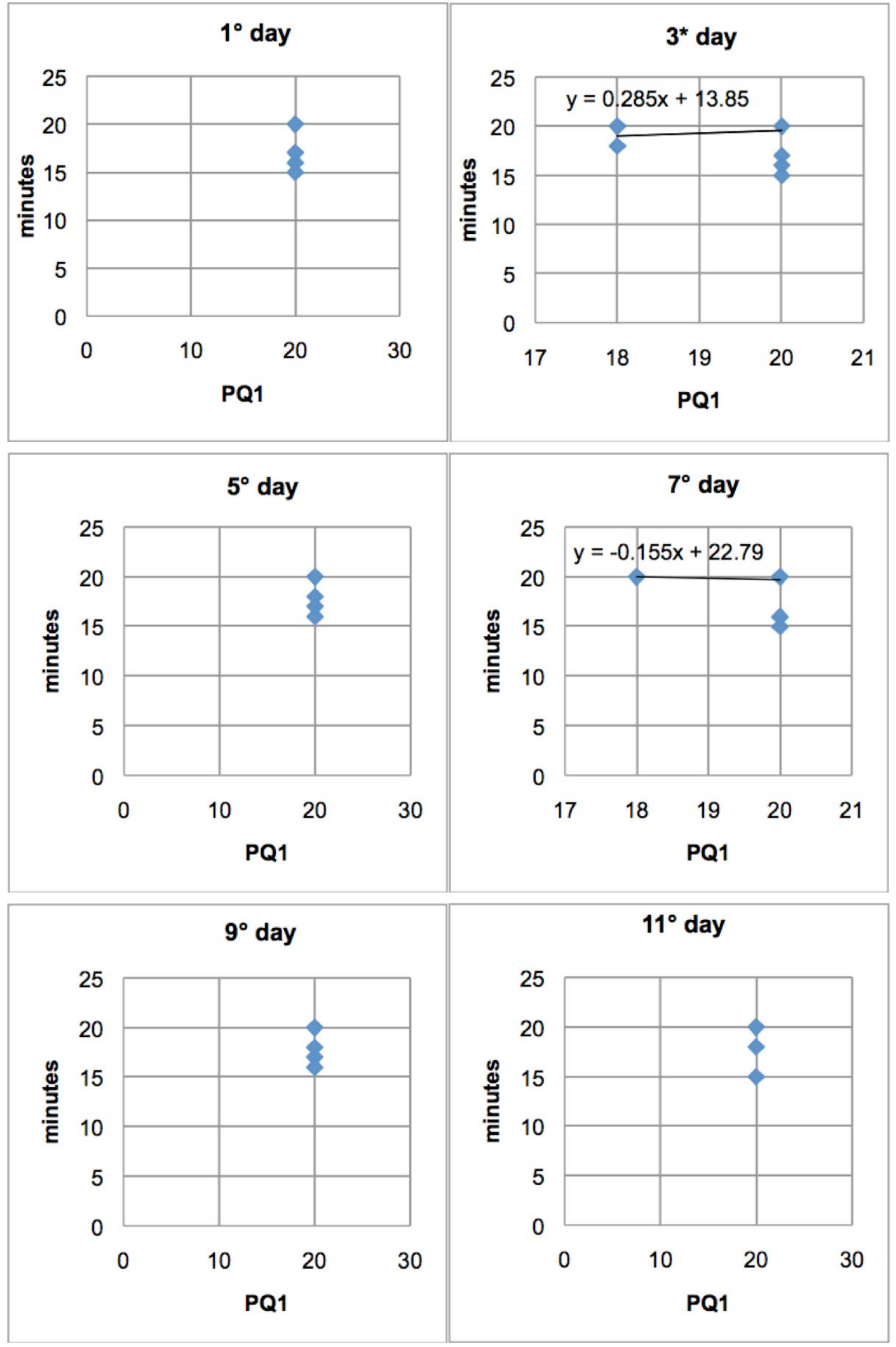
(Figure 2). Continued.

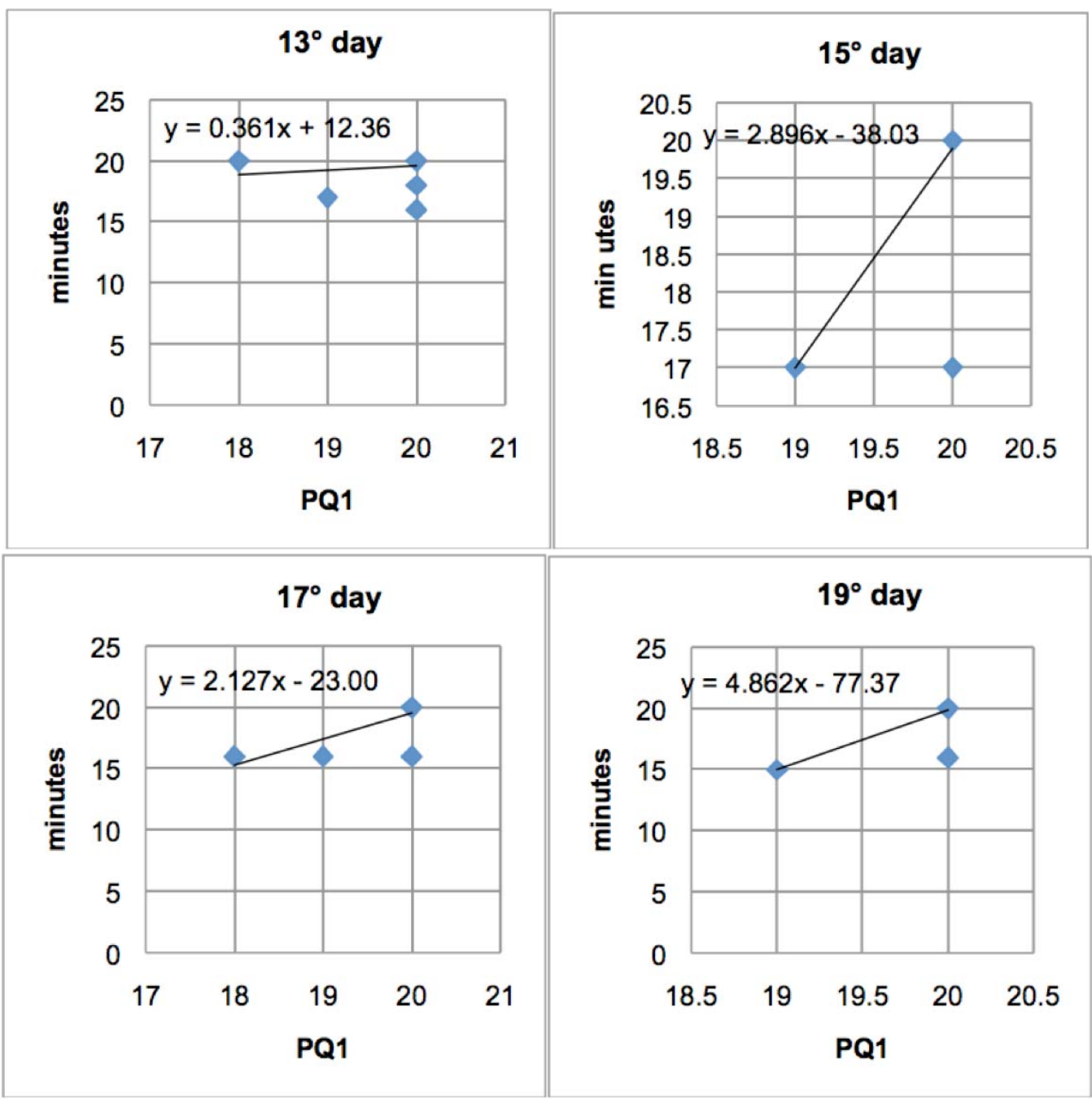

Figure 2: Correlations (Pearson product moment) between PQ1 and writing-time (min) by the healthy matched controls from Test day 1 to Test day 19 (10 days of testing). The correlations were significant only on: Day $15: 0.695^{\circ}$; Day $17: 0.565^{\star}$; Day 19 : $0.772 *$.

${ }^{*} p<0,0001 .{ }^{\circ} p<0.005$, Pearson Product moment correlations.

Table 2: The Performance of AD Patients on the Tests of Cognition, PQ1 and PQ2, the Difference between these Tests, D $\Delta$, and in the Writing Test. Comparisons of the Means of Test Days 1-9 with those of 11-19 Using Scheffe's Test $($ Days $1-9$ vs Days $11-19):{ }^{1} F(9,290)=39.64 ;{ }^{2} F(9,290)=7.14 ;{ }^{3} F(9,290)=76.98 ;{ }^{4} F(9,290)=33.97$

\begin{tabular}{|c|c|c|c|c|c|}
\hline Days of Testing & ${ }^{1} P Q 1$ & ${ }^{2} \mathrm{PQ2}$ & ${ }^{3} \Delta$ & ${ }^{4}$ Writing-time (min) & No. Pat. \\
\hline Day 1 & $11.87 \pm 4.8$ & $4.03 \pm 1.9$ & $7.83 \pm 4.8$ & $8.73 \pm 6.4$ & 30 \\
\hline Day 3 & $10.47 \pm 4.2$ & $4.13 \pm 1.3$ & $6.31 \pm 3.0$ & $8.13 \pm 4.9$ & 30 \\
\hline Day 5 & $9.90 \pm 5.1$ & $4.80 \pm 2.9$ & $5.10 \pm 5.1$ & $8.53 \pm 7.1$ & 30 \\
\hline Day 7 & $9.47 \pm 4.6$ & $5.17 \pm 2.4$ & $4.30 \pm 3.1$ & $5.63 \pm 5.3$ & 30 \\
\hline Day 9 & $11.83 \pm 3.1$ & $5.67 \pm 2.1$ & $6.21 \pm 2.7$ & $8.03 \pm 5.9$ & 30 \\
\hline Mean Days 1-9 & $10.79 \pm 4.3^{\circ}$ & $4.76 \pm 2.1^{*}$ & $5.95 \pm 3.7^{*}$ & $7.81 \pm 5.9^{\star}$ & 30 \\
\hline Day 11 & $8.90 \pm 4.4$ & $5.03 \pm 2.7$ & $3.86 \pm 2.6$ & $5.33 \pm 5.2$ & 30 \\
\hline Day 13 & $9.27 \pm 4.3$ & $5.47 \pm 2.7$ & $3.80 \pm 3.0$ & $5.56 \pm 5.8$ & 30 \\
\hline Day 15 & $8.90 \pm 4.4$ & $5.10 \pm 2.9$ & $3.80 \pm 2.8$ & $5.36 \pm 5.6$ & 30 \\
\hline Day 17 & $9.47 \pm 4.0$ & $5.37 \pm 3.0$ & $4.10 \pm 2.7$ & $6.43 \pm 5.5$ & 30 \\
\hline Day 19 & $9.43 \pm 5.3$ & $4.50 \pm 3.4$ & $4.93 \pm 2.9$ & $7.4 \pm 7.4$ & 30 \\
\hline Mean Days 11-19 & $9.19 \pm 4.4$ & $5.09 \pm 2.9$ & $4.09 \pm$ & $6.01 \pm 5.9$ & \\
\hline
\end{tabular}

${ }^{*} p<0.0001 ;{ }^{\circ} p<0.01$, versus combined mean from Test days 11-19. 
Table 3: The Performance of Healthy Control Group on the Tests of Cognition, PQ1 and PQ2, the Difference between these Tests, $\mathrm{D} \Delta$, and in the Writing Test. Comparisons of the Means of Test Days 1-9 with those of 11-19 Using Scheffé's Test (Days 1-9 vs Days 11-19): ${ }^{1} \mathrm{~F}(9,290)=2.98 ;{ }^{2} \mathrm{~F}(9,290)=2.98 ;{ }^{3} \mathrm{~F}(9,290)=1.53 ;{ }^{4} \mathrm{~F}(9$, 290) $=0.09$

\begin{tabular}{|c|c|c|c|c|c|}
\hline Days of Testing & ${ }^{1} \mathrm{PQ1}$ & ${ }^{2} \mathrm{PQ2}$ & ${ }^{3} \Delta$ & ${ }^{4}$ Writing-time (min) & No. Cont. \\
\hline Day 1 & $20 \pm 0$ & $19.9 \pm 0.5$ & $0.1 \pm 0.5$ & $19.6 \pm 1.2$ & 30 \\
\hline Day 3 & $19.86 \pm 0.5$ & $19.76 \pm 0.6$ & $0.1 \pm 0.3$ & $19.53 \pm 1.3$ & 30 \\
\hline Day 7 & $19.93 \pm 0.3$ & $19.86 \pm 0.5$ & $0.06 \pm 0.6$ & $19.7 \pm 1.1$ & 30 \\
\hline Day 9 & $20 \pm 0$ & $19.86 \pm 0.33$ & $0.13 \pm 0.3$ & $19.63 \pm 1$ & 30 \\
\hline Day 13 & $19.9 \pm 0.4$ & $19.8 \pm 0.7$ & $0.1 \pm 0.4$ & $19.56 \pm 1.2$ & 30 \\
\hline Day 15 & $19.96 \pm 0.1$ & $19.87 \pm 0.5$ & $0.1 \pm 0.4$ & $19.8 \pm 08$ & 30 \\
\hline Day 17 & $19.9 \pm 0.4$ & $18.7 \pm 0.8$ & $0.2 \pm 0.5$ & $19.33 \pm 1.5$ & 30 \\
\hline Day 19 & $19.96 \pm 0.1$ & $19.8 \pm 0.5$ & $0.13 \pm 0.4$ & $19.7 \pm 1.1$ & 30 \\
\hline
\end{tabular}

${ }^{*} p<0.01$, versus combined mean from Test days $11-19$.

performance of the healthy controls on the tests of cognition, PQ1 and PQ2, the difference between these tests, $\mathrm{D} \Delta$, and in the writing test.

\section{Correlational Analyses: MMSE and PQ1, Writing- Time and PQ2}

Marked and significant correlations were obtained between MMSE scores and the performances on PQ1, minutes writing and PQ2 in both $A D$ patients and the control group (see Table 4).

\section{DISCUSSION}

The extent of dysgraphia and deficits in cognitive performance were examined in $A D$ patients and matched healthy controls. It was observed that: (1) The $A D$ patients presented marked and significant linear relationships between the initial cognitive performance (PQ1) and extent of dysgraphia over nine days of testing with the exception of Test day 13 whereas these relationships were not evident in the healthy controls. (2) The AD patients showed marked deficits in all four tests of cognition, PQ1, PQ2, D 4 , which expresses the deterioration from PQ1 to PQ2 testing, and letter-writing, compared with the healthy controls.
(3) It was observed also that for the AD patients' PQ1, $\mathrm{D} \Delta$ and writing-time, that performance deteriorated from Test Days 1-9 to 11-19, but improved slightly for $P Q 2$, whereas for the healthy controls, it was observed that the performance of PQ1 and PQ2 was slightly, significantly worse from Test days $1-9$ to 11-19; whether or not this slight deterioration over test days by the control subjects represents anything more than some expression of the monotony of the tasks for these individuals is difficult to assess. Nevertheless, the marked deterioration for PQ1, D $\Delta$ and extent dysgraphia by the AD patients suggests some clinical relevance in disease progression. (4) Marked and significant correlation between MMSE scores and PQ1, writing time and $\mathrm{PQ} 2$ were obtained.

Dysgraphia appears to be associated with alterations in motor function, as well as language, domains in $A D$; the consideration of the heterogeneous aspect of this expression of this condition offers novel insights of the cognitive nature of disorder, including linguistic processing, motor programming and motor kinematics. Pauc and Young [44] have observed that the medial walls of the cerebral hemispheres, notably the cingulate gyri, contain species-specific neuron fields that to date are not well known within the

Table 4: Correlations between MMSE Scores and the Performances on PQ1, Minutes Writing and PQ2

\begin{tabular}{|c|c|c|c|}
\hline & MMSE - PQ1 & MMSE - Writing time & MMSE - PQ2 \\
\hline \hline AD patients & $0.792^{\star * *}$ & $0.790^{\star * *}$ & $0.788^{\star * *}$ \\
\hline Controls & $0.711^{* \star}$ & $0.708^{\star *}$ & $0.649^{*}$ \\
\hline
\end{tabular}

${ }^{* \star *} \mathrm{p}<0.0000003 ;{ }^{* *} \mathrm{p}<0.00001 ;{ }^{*} \mathrm{p}<0001$, two-tailed tests. 
scientific community and yet have been implicated as the underlying cause of such varying conditions as dysgraphia and autism in children and obsessivecompulsive disorder and AD in adults. Lambert et al. [8] tested mild-to-moderate stage $A D$ patients $(n=59)$ and healthy elderly controls over an extensive assessment of both the central and peripheral components of writing. The healthy elderly controls performed significantly better than the AD patients over a broad spectrum of writing measures. Despite the occurrence of predominantly lexical disorders, there were multiple indications of linked disorders located at different stages in the writing/spelling system (e.g. phonological route, graphemic buffer, allographic store, graphic motor patterns). The authors concluded that there exist heterogeneous profiles of dysgraphia with primary signs of writing impairment in $A D$ originating from changes at different points in the brain networks that subserve writing and spelling performance [8]. It has been shown too that sensory-motor plasticity is impaired in the motor cortex (see below parietal cortex glucose hypometabolism) of AD at an early stage of the disease [45], with evidence for altered parietal-motor connections in AD implicating related motor deficits in dysgraphia [46]. Suh et al. [47] performed Hanja (ideogram) and Hangul (phonogram) reading/writing tasks on six Semantic dementia (SD) patients and nine $A D$ patients, in order to distinguish between $A D$ and semantic dementia. SD patients manifested Hanja alexia/agraphia whereas Hangul reading/writing ability was relatively preserved. There were group differences between SD and AD patients in the Hanja tasks but not in the Hangul tasks. In the former, SPM analysis (a directed writing and continuous writing technique) revealed no evidence of hypometabolism in the posterior fusiform gyrus, but only in the middle and the anterior part of the temporal gyrus. Finally, significant differences between AD patients and healthy control individuals have been found for visuomotor task measures demonstrating large effect size deficits by $A D$ patients especially with visuomotor task progression through its varying conditions [48].

During the clinical course of $A D$, dysgraphia occurs during both the earlier as well as the later stages of disorder progression [49-51]; it is linked to attention and memory deficits that develop during the staging of $A D$ [52]. The regional and functional disturbances in writing disorders have been described quite comprehensively [53] Nevertheless, decline in semantic memory is a key feature of $A D$, and reading and writing performance deterioration as the extent dysgraphia progresses, reflects this loss [54, 55]. Dysgraphia has been suggested to be a more sensitive indication of language deficits in AD than anomia [9]. In a sample of $75 \mathrm{AD}$ patients and 20 healthy controls, Yoon et al. [56] presented Korean participants with Hangul writing tasks. They observed that the writing performance of the $A D$ group was significantly defective with a profusion of different types of errors emerging with disorder progression. Concurrent analysis of PET imaging studies of glucose metabolism indicated that the hypometabolism in the right occipitotemporal lobe and left temperoparietal lobe was linked to Hangul writing impairment, in accordance with lesions studies of dysgraphia [57]. In a sample of 35 patients presenting early onset $A D$, with a severe degree of hypometabolism in the parietal brain region, exhibited not only linguistic errors but also visuoconstructional manifestations (derived from Hangul scripts) of dysgraphia that were associated with cognitive impairments in multiple domains [34]. Finally, Hayashi et al. [58] studied a group of Japanese patients presenting mild $A D$ and 22 healthy controls for performance of Kana writing performance dictation and copying Kanji or dictational Kanji. They found that writing to dictated Kanji words was impaired although Kana writing to dictation and copying Kanji were preserved in these $A D$ patients; impaired writing of dictated Kanji words was associated with dysfunctional cortical activity predominantly in the left frontal, parietal and temporal brain regions [58]. These observations appear to be consistent with those derived from several other Japanese studies pertaining to dysgraphia in $A D$ and applying this type of writing [59-61]. It is relevant in considering the utility of dysgraphia and the cognitive performance tests that marked and significant correlations between MMSE scores and PQ1, writing time and PQ2 were obtained (see Table 4).

In summary, the present study describes strong relationships between dysgraphia and initial cognitive performance (PQ1) in AD patients, but not matched healthy controls, over all the days of testing were observed. Concurrently, consistent deficits by these patients over PQ1, PQ2, D $\Delta$ and writing-time compared the group of healthy control subjects were obtained. Furthermore, the performances of the $A D$ patients on the PQ1, D $\Delta$ and writing-time, but not the PQ2, tests deteriorated from the $1^{\text {st }}$ five days of testing (Days 1-9) to the $2^{\text {nd }}$ five days (11-19). Marked relationships were obtained also between MMSE scores and PQ1, writingtime and $P Q 2$ for both $A D$ patients and healthy controls. These observations fit effectively with those observed previous regarding the production of oral and written words in AD patients [62]. Possibly, the manifest benefits arising from a non-invasive, motor system-generated intervention, e.g. physical exercise 
programs, may offer a suitable alternative for these patients to maintain a degree of functionality [63].

\section{ACKNOWLEDGEMENTS}

Special thanks are due to the patients who participated and the UVA structures.

\section{CONFLICT OF INTEREST}

There is no conflict of interest.

\section{REFERENCES}

[1] LaBarge E, Smith DS, Dick L, Storandt M. Agraphia in dementia of the Alzheimer type. Arch Neurol 1992; 49: 115156.

http://dx.doi.org/10.1001/archneur.1992.00530350065021

[2] Nicolson RI, Fawcett AJ. Dyslexia, dysgraphia, procedural learning and the cerebellum. Cortex 2011; 47(1): 117-27. http://dx.doi.org/10.1016/j.cortex.2009.08.016

[3] Alzheimer A. Uber eine eigenartige Erkrankung der Hirnrinde. Allgemeine Zeitschrift für Psychiatrisch und Psychischgerichtlich Medizin 1907; 64: 146-48.

[4] Ellis AW. Spelling and writing (and reading and speaking) A.W. Ellis (Ed.), Normality and pathology in cognitive functions, Academic Press, London 1982; pp. 113-146.

[5] Roeltgen DP. Agraphia.Heilman-Valenstein Ed, Clinical neuropsychology, University Press, New York 2003; pp. 126145.

[6] Croisile B. Writing, aging and Alzheimer's disease. Psychol Neuropsychiatr Vieil 2005; 3: 183-97.

[7] McNeil MR, Tseng $\mathrm{CH}$. Acquired neurogenic dysgraphias. Aphasia and related neurogenic language disorders, La Pointe Ed Thieme Medical Publishers, New York 1990; pp. 147-176.

[8] Lambert J, Giffard B, Nore F, de la Sayette V, Pasquier F, Eustache F. Central and peripheral agraphia in Alzheimer's disease: from the case of Auguste D. to a cognitive neuropsychology approach. Cortex 42007; 3(7): 935-51. http://dx.doi.org/10.1016/S0010-9452(08)70692-0

[9] Croisile B, Brabant MJ, Carmoi T, Lepage Y, Aimard G, Trillet M. Comparison between oral and written spelling in Alzheimer's disease. Brain Lang 1996; 54: 361-87. http://dx.doi.org/10.1006/brln.1996.0081

[10] Kumar V, Giacobini E. Use of agraphia in subtyping of Alzheimer's disease. Arch Gerontol Geriatr 1990; 11: 155-59. http://dx.doi.org/10.1016/0167-4943(90)90008-T

[11] Kemper S, LaBarge E, Ferraro FR, Cheung $\mathrm{H}$, Cheung $\mathrm{H}$, Storandt M. On the preservation of syntax in Alzheimer's disease. Arch Neurol 1993; 50: 81-86. http://dx.doi.org/10.1001/archneur.1993.00540010075021

[12] Croisile B, Carmoi T, Adeleine $P$, Trillet $M$. Spelling in Alzheimer's disease. Behav Neurol 1995; 8: 135-43.

[13] Henderson VW, Buckwalter JG, Sobel E, Freed DM, Diz MM. The agraphia of Alzheimer's disease. Neurology 1992; 42: 776-84.

http://dx.doi.org/10.1212/WNL.42.4.776

[14] Horner J, Heyman A, Dawson D, Rogers H. The relationship of agraphia to the severity of dementia in Alzheimer's disease. Arch Neurol 1988; 45: 760-63. http://dx.doi.org/10.1001/archneur.1988.00520310066019

[15] Neils J, Boller F, Gerdeman B, Cole M. Descriptive writing abilities in Alzheimer's disease. Clin Exper Neuropsychol 1989; 11: 692-98.

http://dx.doi.org/10.1080/01688638908400925
[16] Fukui T, Lee E. Progressive agraphia can be a harbinger of degenerative dementia. Brain Lang 2008; 104(3): 201-10. http://dx.doi.org/10.1016/j.bandl.2007.10.005

Neils-Strunjas J, Groves-Wright K, Mashima P, Harnish S. Dysgraphia in Alzheimer's disease: a review for clinical and research purposes. J Speech Lang Hear Res 2006; 49(6): 1313-30.

http://dx.doi.org/10.1044/1092-4388(2006/094)

[18] Shim H, Hurley RS, Rogalski E, Mesulam MM. Anatomic, clinical, and neuropsychological correlates of spelling errors in primary progressive aphasia. Neuropsychologia 2012; 50(8): 1929-35.

http://dx.doi.org/10.1016/j.neuropsychologia.2012.04.017

[19] Greenwald ML. Semantic agraphia in Alzheimer's disease. University of Florida, Doctoral Dissertation 1992.

[20] Kertesz A, Appel J, Fisman M. The dissolution of language in Alzheimer's disease. Can J Neurol Sci 1986; 13: 415-18.

[21] Archer T, Kostrzewa RM. Staging neurological disorders: expressions of cognitive and motor disorder. Neurotox Res 2010; 18(2): 107-11.

http://dx.doi.org/10.1007/s12640-009-9134-x

[22] Archer T, Kostrzewa RM, Beninger RJ, Palomo T. Staging neurodegenerative disorders: structural, regional, biomarker, and functional progressions. Neurotox Res 2011; 19: 211-34. http://dx.doi.org/10.1007/s12640-010-9190-2

[23] Forbes KE, Scanks MF, Venneri A. The evolution of dysgraphia in Alzheimer's disease. Brain Res Bull 2004; 63 : 19-24. http://dx.doi.org/10.1016/j.brainresbull.2003.11.005

[24] Silveri M, Corda F, Nardo MD. Central and peripheral aspects of writing disorders in Alzheimer's disease. J Clin Exp Neuropsychol 2007; 29: 179-86. http://dx.doi.org/10.1080/13803390600611351

[25] Appel J, Kertesz A, Fisman M. A study of language function in Alzheimer patients. Brain Lang 1982; 17: 73-91. http://dx.doi.org/10.1016/0093-934X(82)90006-2

[26] Hodges JR, Salmon DP, Butters N. Recognition and naming of famous faces in Alzheimer's a cognitive analysis. Neuropsychologia 1993; 31: 775-88. http://dx.doi.org/10.1016/0028-3932(93)90128-M

[27] Cummings JL, Benson DF, Hill MA, Read S. Aphasia in dementia of the Alzmeimer type. Ann Neurol 1985; 35: 39497.

[28] Faber-Langendoen K, Morris JC, Knesevich JW, LaBarge E, Miller JP, Berg L. Aphasia in senile dementia of the Alzheimer type. Ann Neurol 1988; 23: 365-70. http://dx.doi.org/10.1002/ana.410230409

[29] Beauvois MF, Derouesne J. Lexical or orthographic agraphia. Brain 1981; 104: 21-49. http://dx.doi.org/10.1093/brain/104.1.21

[30] Baxter DM, Warrington EK. Category specific phonological dysgraphia. Neuropsychologia 1985; 23: 653-66. http://dx.doi.org/10.1016/0028-3932(85)90066-1

[31] Ellis AW, Young AW, Flude BM. "Afferent dysgraphia" in a patient and in normal subjects. Cogn Neuropsychol 1987; 4: 465-86.

\section{http://dx.doi.org/10.1080/02643298708252048}

[32] Margolin DM. The neuropsychology of writing and spelling: somantic, phonological, motor and perceptual processes. Quart J Exp Psychol 1984; 36: 459-89.

[33] Braak H, Braak E. Neuropathological stageing of Alzheimer's-related changes. Acta Neuropathol 1991; 82: 239-59.

http://dx.doi.org/10.1007/BF00308809

[34] Yoon JH, Suh MK, Jeong Y, Ahn HJ, Moon SY, Chin J, et al. Agraphia in Korean patients with early onset Alzheimer's disease. Int Psychogeriatr 2011; 23: 1317-26.

http://dx.doi.org/10.1017/S1041610211000822 
[35] Luzzatti C, Laiacona M, Agazzi D. Multiple patterns of writing disorders in dementia of the Alzheimer type and their evolution. Neuropsychologia 2003; 41: 759-72. http://dx.doi.org/10.1016/S0028-3932(02)00328-7

[36] Roeltgen DP, Heilman KM. Lexical agraphia. Further support for the two system hypothesis of linguistic agraphia. Brain 1984; 107: 811-27.

http://dx.doi.org/10.1093/brain/107.3.811

[37] Beeson PM, Rapcsak SZ, Plante E, Chargualaf J, Chung A, Johnson SC, et al. The neural substrates of writing: a functional magnetic resonance imaging study. Aphasiology 2003; 17: 647-65. http://dx.doi.org/10.1080/02687030344000067

[38] Hillis AE, Chang S, Breese E, Heidler J. The crucial role of posterior frontal regions in modality specific components of the spelling process. Neurocase 2004; 10: 175-87.

[39] McKhann G, Drachman D, Folstein M, Katzman R, Price D, Stadlan EM. Clinical diagnosis of Alzheimer's disease: report of the NINCDS-ADRDA Work Group under the auspices of Department of Health and Human Services Task Force on Alzheimer's Disease. Neurology 1984; 34(7): 939-44. http://dx.doi.org/10.1212/WNL.34.7.939

[40] Gaugler JE, Kane RL, Johnston JA, Sarsour K. Sensitivity and specificity of diagnostic accuracy in Alzheimer's disease: a synthesis of existing evidence. Am J Alzheimers Dis Other Demen 2013; 28(4): 337-47. http://dx.doi.org/10.1177/1533317513488910

[41] Folstein MF, Folstein SE, McHugh PR. Mini-mental state. A practical method for grading the cognitive state of patients for the clinician. J Psychiatr Res 1975; 12(3): 189-98. http://dx.doi.org/10.1016/0022-3956(75)90026-6

[42] Activities of Daily Living Evaluation. Encyclopedia of Nursing \& Allied Health. ed. Kristine Krapp. Gale Group, Inc 2002.

[43] Roley SS, DeLany JV, Barrows CJ, et al. Occupational therapy practice framework: domain \& practice. Am J Occup Ther 2008; 62(6): 625-83.

http://dx.doi.org/10.5014/ajot.62.6.625

[44] Pauc R, Young A. Little-known neurons of the medial wall: a literature review of pyramidal cells of the cingulate gyrus. $J$ Chiropr Med 2010; 9(3): 115-20. http://dx.doi.org/10.1016/i.jcm.2010.05.001

[45] Bonnì S, Lupo F, Lo Gerfo E, Martorana A, Perri R, Caltagirone C, Koch G. Altered parietal-motor connections in Alzheimer's disease patients. J Alzheimers Dis 2013; 33(2): 525-33. doi: 10.3233/JAD-2012-121144.

[46] Carmen T, Antonino S, Francesca M, Vincenzo R, Roberta $A$, Grazia AM, et al. Impairment of sensory-motor plasticity in mild Alzheimer's disease. Brain Stimul 2013; 6(1): 62-6. http://dx.doi.org/10.1016/j.brs.2012.01.010

[47] Suh MK, Kim EJ, Lee BH, Seo SW, Chin J, Kang SJ, Na DL. Hanja (Ideogram) alexia and agraphia in patients with semantic dementia. Neurocase 2010; 16(2): 146-56. http://dx.doi.org/10.1080/13554790903339629

[48] Tippett WJ, Sergio LE, Black SE. Compromised visually guided motor control in individuals with Alzheimer's disease: can reliable distinctions be observed? J Clin Neurosci 2012; 19(5): 655-60.

http://dx.doi.org/10.1016/i.jocn.2011.09.013
[49] Hughes JC, Graham N, Patterson K, Hodges J. Dysgraphia in mild dementia of Alzheimer's type. Neuropsychologia 1997; 4: 533-45 http://dx.doi.org/10.1016/S0028-3932(96)00102-9

[50] Small JA, Sandhu N. Episodic and semantic memory influences on picture naming in Alzheimer's disease. Brain Lang 2008; 104: 1-9.

http://dx.doi.org/10.1016/j.bandl.2006.12.002

[51] Yasuda K, Nakamura T, Beckman B. Brain processing of proper names. Aphasiology 2000; 14: 1067-89. http://dx.doi.org/10.1080/02687030050174638

[52] Silveri MC, Corda F, Di Nardo M. Central and peripheral aspects of writing disorders in Alzheimer's disease. J Clin Exp Neuropsychol 2013. http://dx.doi.org/10.1080/13803390600611351

[53] Luzzatti C. Acquired reading and writing disorders. In: Handbook of the Neuroscience of Language, (Eds. B Stemmer, HA Whitaker), Elsevier: New York 2008; pp. 209218.

http://dx.doi.org/10.1016/B978-0-08-045352-1.00020-3

[54] Harnish SM, Neils-Strunjas J. In search of meaning: reading and writing in Alzheimer's disease. Semin Speech Lang 2008; 29(1): 44-59.

http://dx.doi.org/10.1055/s-2008-1061624

[55] Grossman M. Language in dementia. In: Handbook of the Neuroscience of Language, (Eds. B Stemmer, HA Whitaker), Elsevier: New York 2008; pp. 279-288. http://dx.doi.org/10.1016/B978-008045352-1.00027-6

[56] Yoon JH, Kim HH, Seo SW, Chin J, Kim JH, Lee KH, et al. Dysgraphia in Korean patients with Alzheimer's disease as a manifestation of bilateral hemispheric dysfunction 2012.

[57] Alexander MP, Friedman RB, Loverso F, Fisher RS. Lesion location of phonological dysgraphia. Brain Lang 1992; 43: 83-95.

http://dx.doi.org/10.1016/0093-934X(92)90022-7

[58] Hayashi A, Nomura H, Mochizuki R, Ohnuma A, Kimpara T, Ootomo $\mathrm{K}$, et al. Neural substrates for writing impairments in Japanese patients with mild Alzheimer's disease: a SPECT study. Neuropsychologia 2011; 49: 1962-68.

http://dx.doi.org/10.1016/j.neuropsychologia.2011.03.024

[59] Sakurai Y, Mimura I, Mannen T. Agraphia for Kanji resulting from a left posterior middle temporal gyrus lesion. Behav Neurol 2008; 19: 93-106.

[60] Sakurai Y, Onuma Y, Nakazawa G, Ugawa Y, Momose T, Tsuji S, et al. Parietal dysgraphia: characterization of abnormal writing stroke sequences, character formation and character recall. Behav Neurol 2007; 18: 99-114.

[61] Yaguchi H, Yaguchi M, Bando M. A case of pure agraphia due to left parietal lobe infarction. Brain Nerve 2006; 58: 88592.

[62] Croisile B, Ska B, Brabant MJ, Duchene A, Lepage $Y$, Aimard G, Trillet M. Comparative study of oral and written production in patients with Alzheimer's disease. Brain Lang 1996; 53: 1-19.

http://dx.doi.org/10.1006/brln.1996.0033

[63] Archer T. Physical exercise alleviates debilities of normal aging and Alzheimer's disease. Acta Neurol Scand 2011; 123: 221-38. DOI: 10.1111/j.1600-0404-2010.01412.x.

\section{DOI: http://dx.doi.org/10.6000/2292-2598.2013.01.02.4}

(c) 2013 Onofri et al.; Licensee Lifescience Global.

This is an open access article licensed under the terms of the Creative Commons Attribution Non-Commercial License (http://creativecommons.org/licenses/by-nc/3.0/) which permits unrestricted, non-commercial use, distribution and reproduction in any medium, provided the work is properly cited. 